\title{
Rancang Bangun E-Business Berbasis Web Pada Perusahaan Distributor Pupuk Di Sumatera Selatan
}

\author{
Web-Based E-Business Design At A Fertilizer Distributor Company In South Sumatra
}

\author{
Egi Syahputra Alvian ${ }^{1}$, Yulistia ${ }^{2}$ \\ ${ }^{1,2}$ STMIK GI MDP; Jl. Rajawali No. 14 Palembang, +62(711) 376400 \\ ${ }^{1,2}$ Program Studi Sistem Informasi, STMIK GI MDP, Palembang \\ e-mail: ${ }^{* 1}$ egisaputra1999@gmail.com, 2yulistia@mdp.ac.id
}

\begin{abstract}
Abstrak
Tujuan dari pembuatan sistem ini adalah merancang dan membangun sistem e-business berbasis web agar memudahkan proses-proses yang tercakup dalam e-business seperti pemesanan barang yang dilakukan pelanggan dan mempermudah pemasok dalam menawarkan barangnya. Metode yang digunakan untuk membangun aplikasi adalah metode RUP (Rational Unified Process) dengan melakukan kegiatan dalam metodologi diantaranya observasi dan wawancara serta analisis dan perancangan. Analisis PIECES dilakukan untuk merumuskan permasalahan dan analisis kebutuhan dilakukan terhadap kebutuhan secara fungsional dan non fungsional, serta diagram usecase dan untuk perancangan aplikasi menggunakan diagram activity, diagram sequence, dan diagram class. Aplikasi dibuat menggunakan Framework Code Igniter dan MySQL untuk database. Hasil dari adanya sistem e-business diharapkan dapat membuka peluang masuknya pelanggan dan pemasok baru dari luar kota dan mempermudah pelanggan dalam memperoleh informasi mengenai barang terkait kegiatan $e$-business.
\end{abstract}

Kata kunci: e-business, Pupuk, MySql, RUP.

\begin{abstract}
The purpose of this system development is to design and build a web-based e-business system in order to facilitate the processes involved in e-business, such as ordering goods by customers and making it easier for suppliers to offer their goods. The method used to design and build the application is RUP (Rational Unified Process) method by carrying out activities in the methodology including observation and interviews as well as analysis and design. PIECES analysis is carried out to formulate problems and needs analysis is carried out on functional and non-functional requirements, as well as usecase diagrams and for application design using activity diagrams, sequence diagrams, and class diagrams. The application is built using Code Igniter and MySQL Framework for the database. The results of the e-business system are expected to open up opportunities for new customers and suppliers from outside the city and make it easier for customers to obtain information about goods related to e-business activities.
\end{abstract}

Keywords: E-Business, Fertilizer, MySQL, RUP. 


\section{PENDAHULUAN}

Pesatnya perkembangan teknologi telah menciptakan berbagai media terutama dalam proses menjual barang ataupun memproses data dengan memberikan kemudahan salah satu teknologi tersebut adalah komputer yang membantu menghasilkan informasi dan membuat pekerjaan lebih efisien dan efektif. Media yang biasa digunakan dalam proses bisnis ialah website yang memiliki banyak manfaat seperti menghemat biaya promosi, media yang membantu untuk terhubung ke pelanggan, dan memudahkan dalam mencari mitra. salah satunya bentuk pemanfaatan web e-business. [12]

E-business sendiri pertama kali diperkenalkan oleh Lou Gerstner, CEO perusahaan IBM. Istilah ini, dapat diterjemahkan sebagai kegiatan bisnis yang dilakukan secara otomatis dan semi otomatis dengan menggunakan sistem informasi komputer. E-business memungkinkan suatu perusahaan untuk berhubungan dengan sistem pemrosesan data internal dan eksternal mereka secara lebih efisien dan fleksibel. [14]Adapun keuntungan dari perusahaan jika menerapkan proses e-business seperti perusahaan dapat mempreluas pasarnya, perusahaan dapat lebih mudah dalam mendapatkan pelanggan baru, dan menekan biaya telekomunikasi serta juga waktu transaksi dan penerimaan produk.[11]

Sebuah perusahaan yang bergerak dibidang distributor pupuk dimana jenis-jenis pupuk yang di jual baik itu pupuk subsidi maupun non subsidi, jenis pupuk subsidi seperti Urea dan NPK, dan untuk non subsidi ada $\mathrm{KCl}$, Urea Non, TSP,RP Egypt, dan Dolomite. Masalah yang terdapat pada perusahaan ini dari hasil wawancara pada senin, 7 September 2020, di antaranya kesulitan dalam mendata pemesanan pupuk karena selama ini proses pemesanan pupuk yang dilakukan oleh pelanggan masih menggunakan bantuan telepon ataupun datang langsung ke kantor sehingga perlunya pencatatan pesanan kedalam dokumen pesanan, terbatasnya informasi antara pelanggan dan Perusahaan distributor pupuk mengenai barang yang dijual dan barang yang sedang promo, terjadinya kehabisan stok barang pada Perusahaan distributor pupuk dikarenakan pemasok kehabisan stok, sulitnya mengetahui barang mana saja yang terlaris dan kurang laris dikarenakan pencatatan penjualan yang kurang baik.

Dari keempat permasalahan tersebut serupa dengan permasalahan yang ada pada penulisan skripsi yang berjudul Rancang Bangun E-Business Berbasis Website Studi Kasus Pada PT Pandawa Untuk Indonesia Palembang dengan memberikan manfaat antara lain, mempermudah proses pemesanan dan penjualan, membuat para agen lebih puas dengan control stok barang, pemberian potongan harga, dan pemberian informasi barang baru pada sistem yang di bangun, serta mempermudah proses pembuatan laporan penjualan dan pemesanan (Prakasa $e t$ al 2018).

Adapun permasalahan lain sulitnya mencari pemasok baru dikarenakan keterbatasannya informasi antara pemasok dengan perusahaan, pada permasalahan tersebut serupa dengan permasalahan yang terdapat pada penulisan skripsi yang berjudul Sistem Informasi E-Business Pada CV Central Medica Berbasis Website dengan memberikan manfaat antara lain, membuka peluang masuknya pemasok baru dan mempermudah pemasok dalam menawarkan barangnya dengan sistem yang di bangun (Aprianti et al 2018). Sebagai uraian diatas, pengembangan sistem yang diusulkan penulis dituangkan dalam bentuk yang berjudul "Rancang Bangun EBusiness Berbasis Web Pada Perusahaan Distributor Pupuk Di Sumatera Selatan”.

\section{METODE PENELITIAN}

Dalam pengembangan sistem ini, metode yang digunakan penulis adalah metode Rational Unified Process (RUP). Metode ini memiliki beberapa fase pengembangan, sebagai berikut [4]: 
1. Inception (permulaan)

Pada tahap ini penulis melakukan pemodelan bisnis yang di butuhkan dan mendifinisikan kebutuhan sistem yang akan di buat dengan melakukan wawancara, observasi, dan studi pustaka untuk mendapatkan kebutuhan dari sistem yang akan di bangun.

2. Elaboration (perluasan/perencanaan)

Pada tahap ini penulis melakukan perencanaan sistem dengan bantuan tools seperti PIECES dan use case diagram. Sedangkan untuk perancangan sistem menggunakan bantuan tools seperti activity diagram, sequence diagram, dan class diagram. Ditahap ini juga di definisikan fitur-fitur E-Business_yang akan diterapkan pada program aplikasi yang akan dibangun, seperti:

\subsection{E-Business}

E-Business adalah sebuah pendekatan yang aman, fleksibel, dan terintegrasi untuk memberikan nilai bisnis yang berbeda dengan mengkombinasikan sistem dan proses yang menjalankan operasi bisnis utama dengan pemanfaatan teknologi internet.[7][8][19]

\subsection{E-Marketing}

E-Marketing merupakan pertukaran relasional dalam lingkungan digital, berjaringan (networked), dan interaktif. Fungsi-fungsi utama e-marketing mencakup 11 elemen yang dirumuskan menjadi $4 \mathrm{P}+\mathrm{P}^{2} \mathrm{C}^{2} \mathrm{~S}^{3 .} \cdot[2]$

\subsection{E-Commerce}

E-Commerce atau E-Business adalah proses pembelian dan penjualan barang serta jasa, atau memindahkan dana atau data melalui jaringan elektronik, terutama internet.[1][18]

\subsection{Supply Chain Management}

Supply chain management adalah integrasi proses bisnis dari pengguna akhir melalui pemasok yang memberikan produk, jasa, informasi, dan bahkan peningkatan nilai untuk konsumen dan karyawan. Melalui rantai pasokan, perusahaan dapat membangun kerjasama melalui penciptaan jaringan kerja (network) yang terkordinasi dalam penyediaan barang maupun jasa bagi konsumen secara efisien.[9]

\subsection{Customer Relationship Management}

CRM merupakan enterprise-wide business strategy yang dirancang untuk mengoptimalkan profitabilitas, pendapatan dan kepuasan pelanggan dengan cara mengorganisasikan perusahaan berdasarkan segmen pelanggan, memperkokoh perilaku pemuasan pelanggan, dan mengaitkan proses-proses dari pelanggan sampai pemasok.[2]

\section{Construction (Konstruksi)}

Pada tahap ini penulis mulai melakukan pembuatan sistem dengan fitur-fitur yang sudah di analisis pada tahap sebelumnya. Adapun tools yang digunakan untuk membangun sistem ini seperti aplikasi visual code, xampp, dan bahasa pemrograman php yang nantinya akan menghasilkan sebuah web yang diharapkan sesuai dengan analisis yang dilakukan.[10]

4. Transition (Transisi)

Pada tahap ini penulis melakukan instalasi sistem dan pelatihan agar dapat dimengerti dan digunakan oleh perusahaan. 


\section{HASIL DAN PEMBAHASAN}

\subsection{Profil Perusahaan}

Perusahaan ini merupakan sebuah perusahaan yang bergerak dibidang distributor pupuk. Yang memiliki pengalaman dan kompeten dalam menjual pupuk yang didukung oleh kekuatan armada angkut darat dan sumber daya manusia yang professional. Jenis-jenis pupuk yang di jual baik itu pupuk subsidi maupun non subsidi, jenis pupuk subsidi seperti urea dan npk, dan untuk non subsidi ada kcl, npk non, tsp, rp egype, dan dolomite. Adapun pelanggan yang dimiliki oleh perusahaan ini baik dari perorangan, kios, maupun perusahaan seperti PT dan CV.

\subsection{Analisis Permasalahan}

Penulis menggunakan PIECES (Performance, Information, Economic, Control, Efficiency, dan Service) untuk menganalisi permasalahan yang ada pada Perusahaan distributor pupuk. Berikut merupakan kerangka detail permasalahan.[13]

Tabel 1. PIECES

\begin{tabular}{|c|l|}
\hline PIECES & \multicolumn{1}{|c|}{ Keterangan } \\
\hline Perfomance & $\begin{array}{l}\text { Sulitnya melihat laporan stok barang untuk menentukan barang apa } \\
\text { saja yang mau dibeli karena proses pengecekan barang dilakukan 1 } \\
\text { bulan sekali. }\end{array}$ \\
\hline Information & $\begin{array}{l}\text { Kekurangan informasi mengenai pemasok yang dapat } \\
\text { mensuplai barang. } \\
\text { - Pelanggan kesulitan mendapatkan informasi mengenai barang } \\
\text { yang tersedia. }\end{array}$ \\
\hline Economic & $\begin{array}{l}\text { Kekurangan jumlah pemasok baru menyebabkan harga produk } \\
\text { yang tinggi maka pemasukan yang didapat oleh perusahaan ini } \\
\text { kurang maksimal. }\end{array}$ \\
& $\begin{array}{l}\text { Biaya pembelian pupuk yang tidak dapat dihemat karena } \\
\text { pemasok hanya yang sudah ada saja dengan penawaran harga } \\
\text { yang tidak bersaing. }\end{array}$ \\
\hline Control & $\begin{array}{l}\text { Seringnya terjadi keterlambatan dan kesalahan dalam } \\
\text { perekapan laporan penjualan, pembelian, dan stok barang. }\end{array}$ \\
& $\begin{array}{l}\text { Perusahaan sulit dalam menentukan potongan harga untuk } \\
\text { setiap barang dikarenakan pencatatan penjualan yang kurang } \\
\text { baik. }\end{array}$ \\
\hline Efficiency & $\begin{array}{l}\text { Pemasok menawarkan jenis barang yang sama secara berulang- } \\
\text { ulang karena pemasok tidak memiliki daftar riwayat penawaran } \\
\text { sebelumnya. }\end{array}$ \\
\hline Services & $\begin{array}{l}\text { kerap kali pelanggan merasa kurang puas karena terjadi kesalahan } \\
\text { pencatatan jumlah yang di pesan oleh pelanggan karena } \\
\text { menyebabkan selisih dalam pengiriman. }\end{array}$ \\
\hline
\end{tabular}

\subsection{Analisis Kebutuhan}

\subsubsection{Rancangan dan Fitur E-Business}

Didalam e-business memiliki 4 komponen yang meliputi Customer relationship management, e-marketing, supply chain management, e-commerce yang dimana komponen tersebut dimasukan ke dalam sistem yang dibangun menjadi fitur-fitur sebagai berikut.[6][20] 


\section{Fitur Customer Relationship Management}

a. Memiliki fitur pencarian dimana seorang pelanggan ketika ingin membeli pupuk tetapi tidak tau jenis pupuk mana yang cocok untuk tanamannya maka di sistem yang dibangun penulis memasukan fitur tersebut dengan cara si pelanggan memasukan kata kunci tanamannya maka sistem akan memunculkan barang yang berkaitan.

b. Memiliki fitur diskon barang yang di proses oleh bagian armada.

2. Fitur Supply Chain Management

a. Memiliki fitur penawaran barang kepada perusahaan dengan dan pemasok dapat juga melihat riwayat dari penawaran selain itu juga dapat melihat barang mana saja yang sudah dipesan dan barang mana saja yang belum di pesan

b. Memiliki fitur validasi terhadap pesanan perusahaan.

3. Fitur E-Marketing

a. Memiliki tampilan gambar yang detail terhadap kemasan dan isi di dalam kemasan.

b. Memiliki deskripsi yang jelas berupa kandungan pupuk, manfaat, cara pemakaian, dan cocok untuk tanaman apa saja.

4. Fitur E-Commerce

a. Memilki fitur penjualan yang dapat diakses oleh pelanggan sehingga pelanggan dapat memesan barang melalui sistem yang dibangun.

b. Memiliki fitur pembayaran dengan cara transfer.

c. Memiliki fitur keranjang barang sehingga pelanggan dapat melihat barang apa saja yang mereka masukkan ke keranjang. use case diagram dari Perusahaan distributor pupuk.

\subsubsection{Use Case Diagram Sistem yang Diusulkan [3][4]}

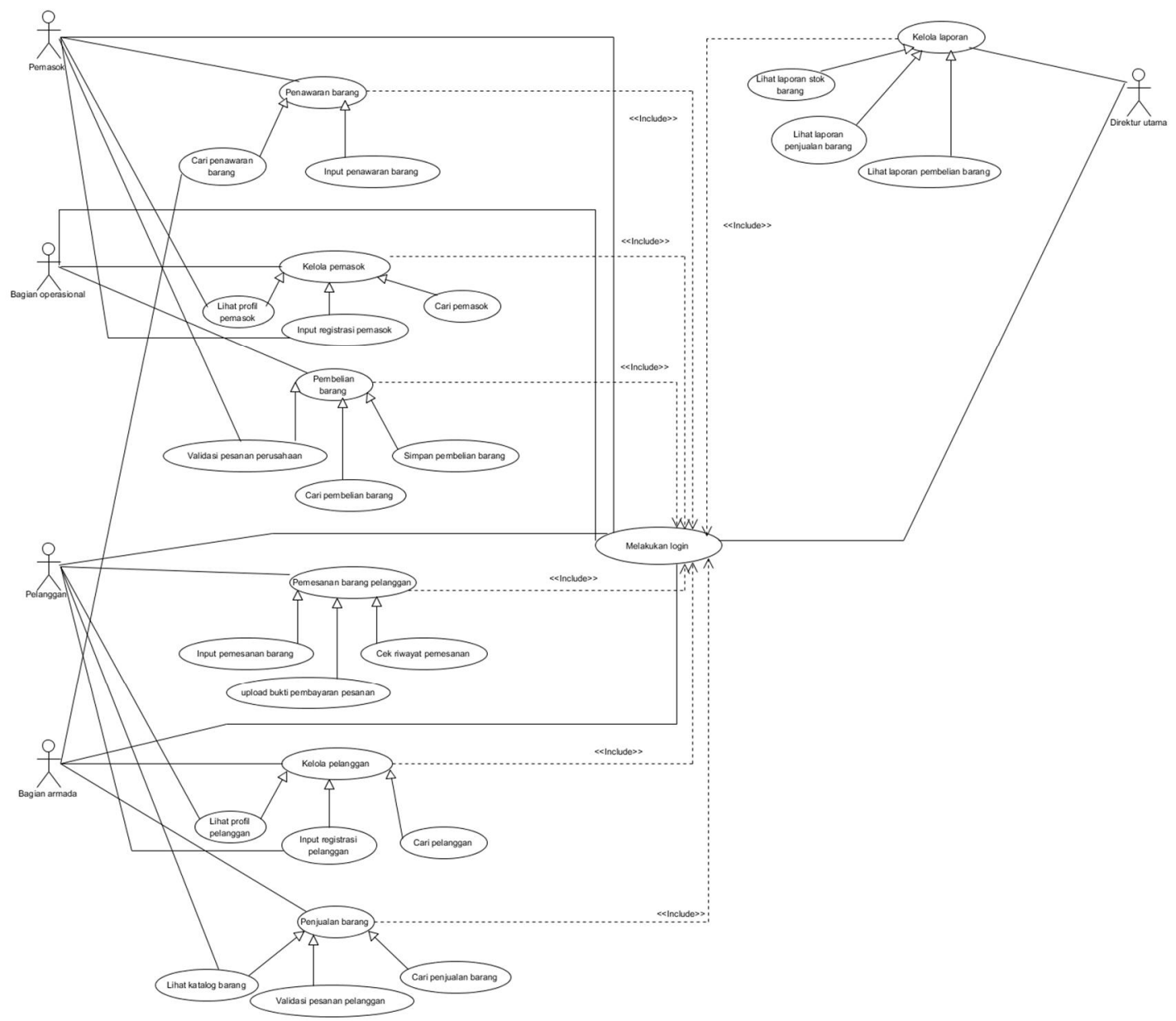

Gambar 1. Use Case Diagram 


\subsubsection{Class Diagram}

Berikut adalah gambar class diagram pada rancang bangun $e$-business pada Perusahaan distributor pupuk [4][5]

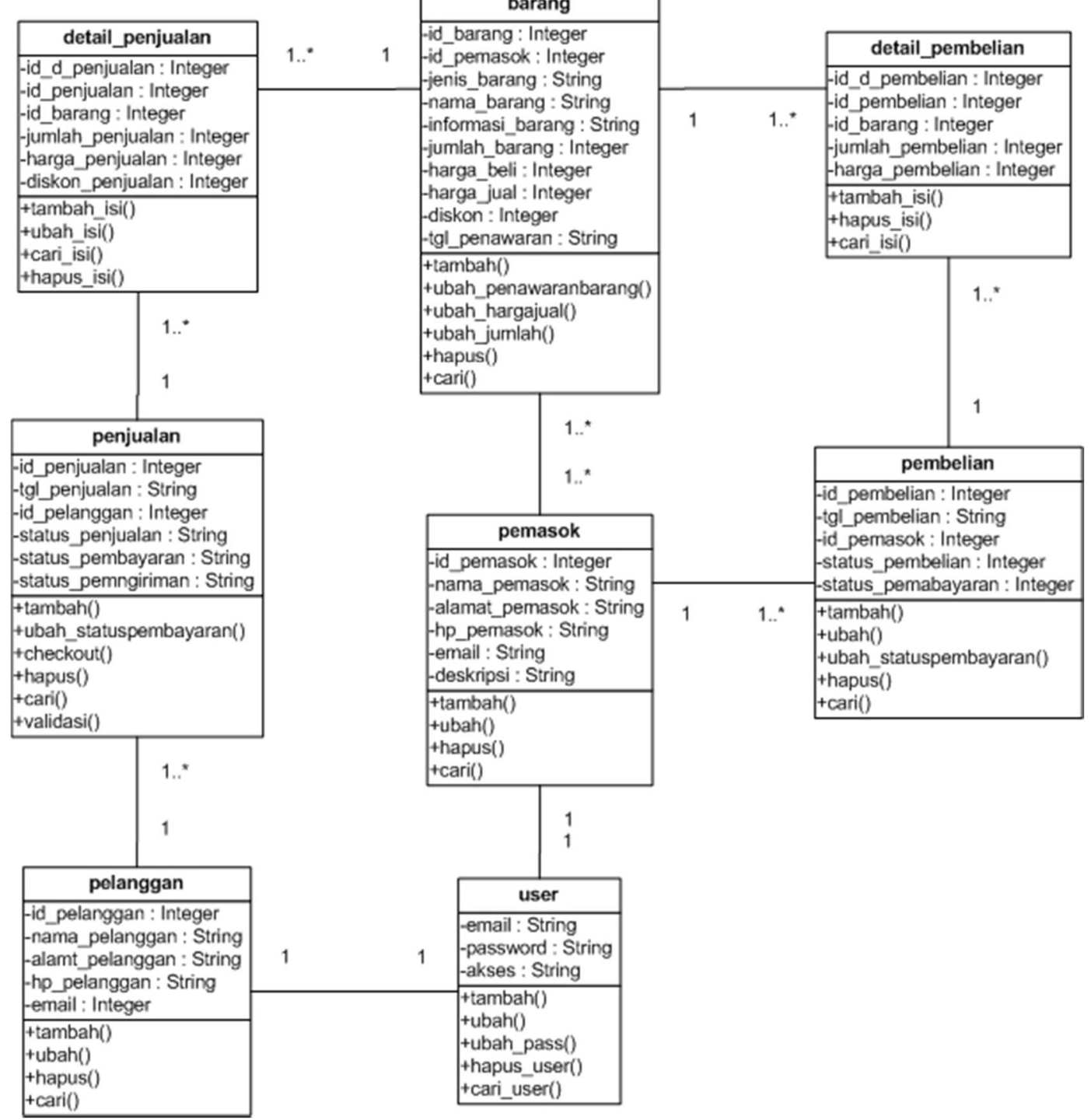

Gambar 2. Class Diagram

\subsubsection{Tampilan Antarmuka Sistem [15][16][17]}

a. Tampilan Fitur Supply Chain Management yaitu Penawaran Barang Pemasok Pada gambar dibawah ini adalah tampilan dimana saat pemasok melakukan penawaran dan tampilan ini mengandung unsur dari supply chian management. 


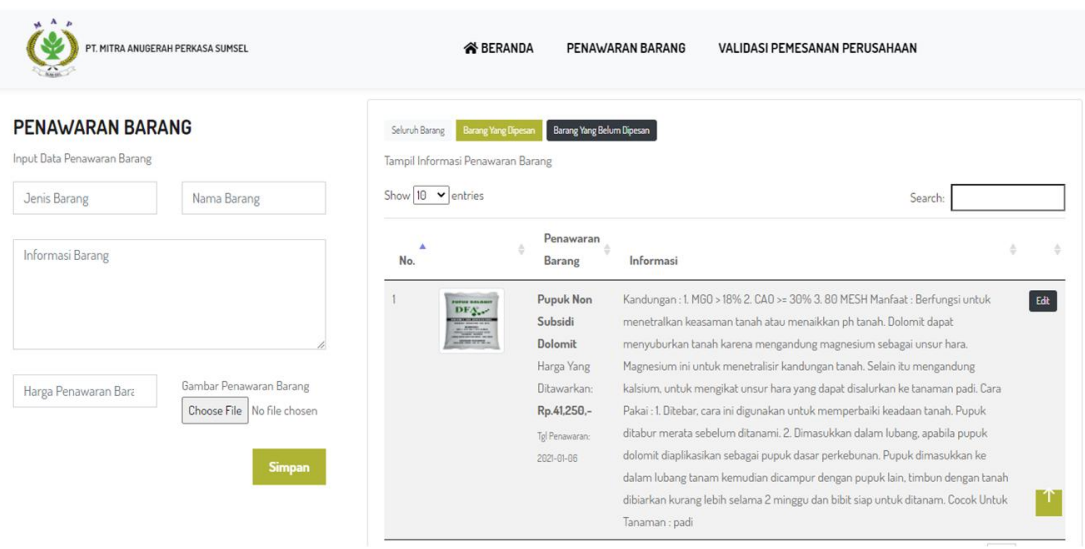

Gambar 3. Antarmuka Penawaran Barang Pemasok

b. Tampilan Fitur Customer Relationship Management yaitu Antarmuka Penawaran Barang Pemasok

Pada gambar dibawah ini adalah tampilan dimana saat pelanggan masuk ke halam beranda dan terdapat jenis-jenis barang yang dijual serta pada halaman ini pelanggan dapat mencari barang berdasarkan kategori jenis pupuk ataupun memasukan jenis tanaman yang dimana fitur tersebut mengandur unsur dari customer relationship management.

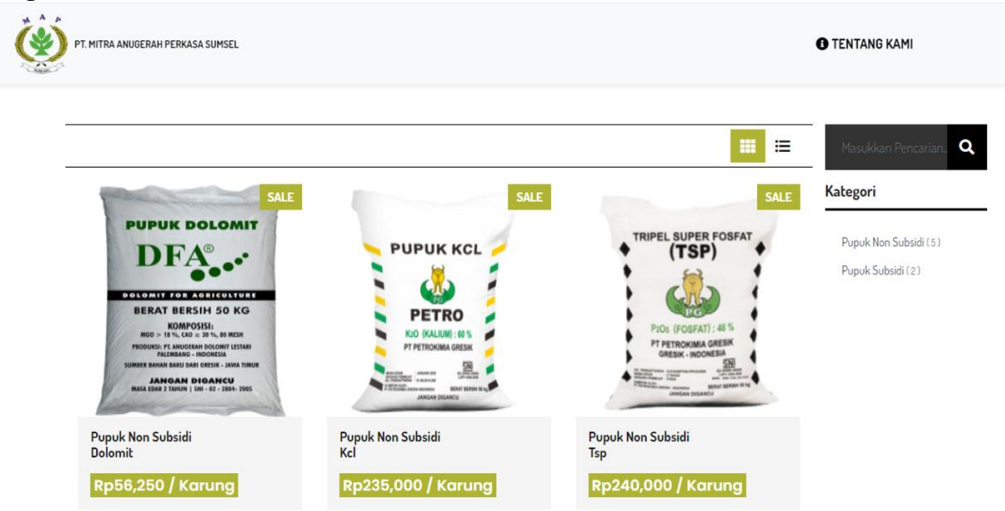

Gambar 4. Antarmuka Beranda

c. Tampilan Fitur e-Marketing, yaitu Antarmuka Detail Barang

Pada gambar dibawah ini adalah tampilan dari detail barang ketika pelanggan ingin membeli barang dan detail barang ini termasuk memiliki unsur dari e-marketing.

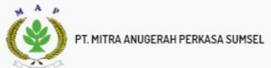

- tentang kamI
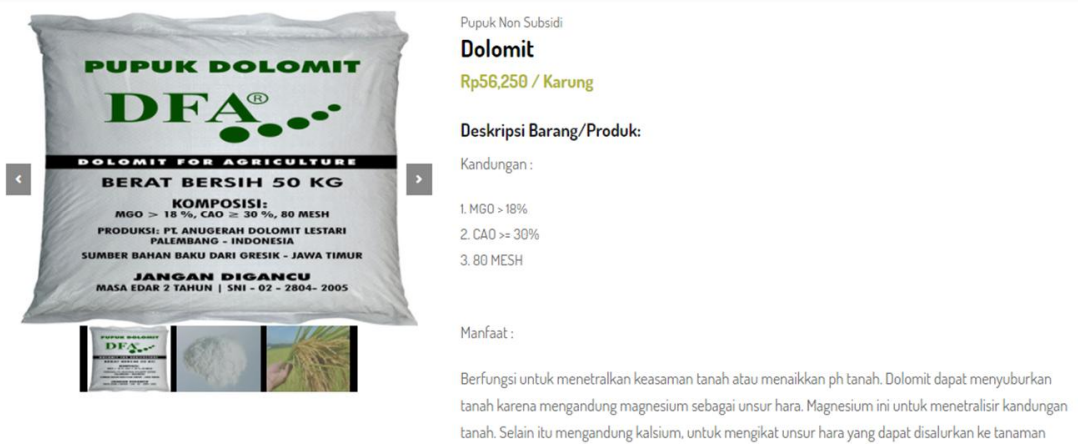

Gambar 5. Antarmuka Detail Barang 
d. Tampilan Fitur E-Commerce yaitu Antarmuka Pembayaran Pesanan Pelanggan Pada gambar dibawah ini adalah tampilan pembayaran pesanan pelanggan setelah melakukan proses pemesanan kepada perusahaan dan tampilan ini memiliki unsur $e$ commerce.

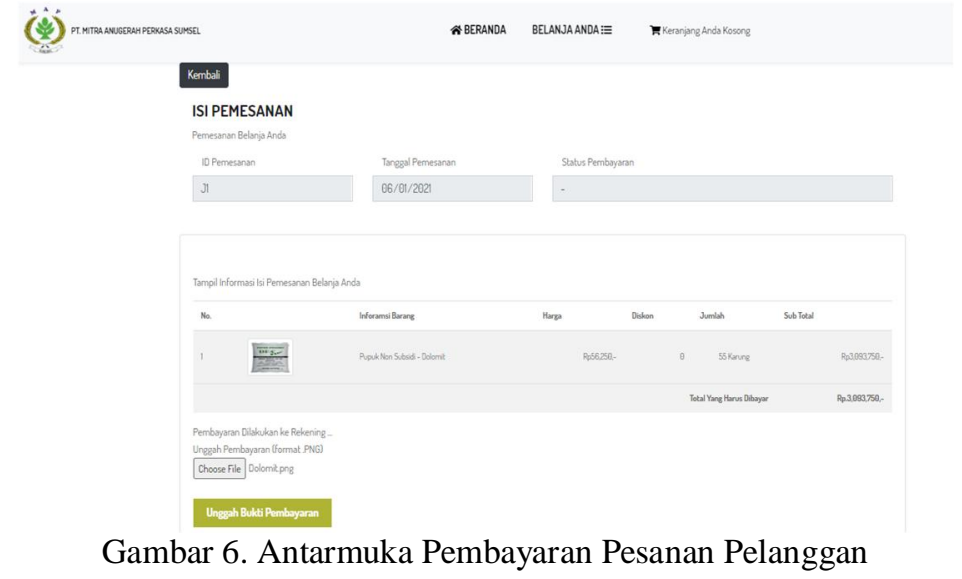

\section{KESIMPULAN DAN SARAN}

\subsection{Kesimpulan}

Berdasarkan hasil yang telah dibuat dapat diambil kesimpulan sebagai berikut.

(1). Direktur utama kesulitan untuk melihat laporan secara detail karena proses perekapan dilakukan 1 bulan sekali dengan adanya sistem yang penulis rancang direktur utama dapat melihat informasi laporan secara detail seperti laporan stok barang, laporan penjualan, dan laporan pembelian.

(2). Bagian operasional kesulitan dalam memesan barang kepada pemasok karena harus menghubungi pemasok melalui email ataupun telepon, dengan adanya sistem ini bagian operasional dapat memesan barang kapan saja.

(3). Perusahaan kesulitan dalam meliaht informasi dari pemasok dengan adanya sistem yang dibangun yang memiliki fitur daftar pemasok dengan detail yang mempermudah perusahaan mengetahui informasi pemasok.

(4). Perusahaan kesulitan dalam merepak laporan dan sering terjadi kesalahan dengan adanya sistem yang dibangun perusahaan tidak sulit lagi dalam merekap laporan penjualan, laporan pembelian, dan laporan stok barang karena semua laporan sudah otomatis terdata disistem.

(5). Pelanggan kesulitan untuk mencari informasi mengenai barang yang ingin dibeli dengan adanya sistem ini pelanggan dapat dengan mudah mencari informasi barang melalui sistem yang dibangun dan pelanggan dengan mudah dapat memesan barang melalui sistem tanpa perlu menghubungi perusahaan lagi.

(6). Pemasok sering kali menawarkan barang yang sama secara berulang karena tidak memiliki riwayat dari proses penawaran dengan adanya sistem yang dibangun penulis pemasok dapat melihat riwayat penawaran yang pernah mereka tawarkan ke perusahaan sehingga pemasok tidak akan menawarkan barang yang sama lebih dari 1 kali.

\subsection{Saran}

Berdasarkan kesimpulan dan hasil analisa yang telah dilakukan, berikut ini saran-saran yang dapat diberikan sebagai berikut.

(1). Perlunya dilakukan pemeliharaan sistem yang lebih baik secara berkala dan pengawasan terhadap penerapan sistem yang diusulkan, sehingga jika ditemukan kelemahan dan permasalahan pada sistem yang diusulkan dapat segera diperbaiki. 
(2). Perlunya pengembangan sistem seperti menambahkan fitur-fitur baru untuk menyesuaikan teknologi informasi yang semakin berkembang.

(3). Perlunya membangun sistem dengan berbasis android untuk kedepannya agar lebih mudah digunakan dimana saja dan kapan saja.

\section{DAFTAR PUSTAKA}

[1] Abdul Halim Barkatullah 2005, Bisnis E-Commerce: Studi Sistem Keamanan dan Hukum Di Indonesia, Pustaka Pelajar, Yogyakarta.

[2] Anastasia Diana, Fandy Tjiptono 2007, E-Business, Andi, Yogyakarta.

[3] Andreas Riel 2010, System, Software and Services Process Improvement, Springer, France.

[4] A.S. Rosa 2013, Rekayasa Perangkat Lunak Terstruktur dan Berorientasi Objek, Informatik, Bandung.

[5] Enterprise, Jubilee 2014, MySQL Untuk Pemula, Elex Media Komptindo, Jakarta.

[6] Grania Shancia Go 2018, Perancangan E-Business pada Hahallo Hot Wheels, Bandung. Diakses 04 September 2020, dari repository.unpar.ac.id.

[7] I Putu Agus Eka Pratama 2015, E-Commerce, E-Business dan Mobile Commerce, Informatika, Bandung.

[8] James A. O’Brien, George M. Marakas 2008, Management Information Systems, Irwin, Northwestern University.

[9] Lina Anatan, Lena Ellitan 2018, Supply Chain Management Perencanaan, Proses dan Kemitraan, Edisi Revisi, Alvabeta, Bandung.

[10] Martina Seidl, Marion Scholz, Christian Huemer, Gerti Kappel 2012, UML @ Classroom: An Introduction to Object-Oriented Modeling, Springer, Germany

[11] M. Eko Branata, Rendy Mirza Revelino, Daniel Udjuwala 2013, Perancangan EBusiness Pada CV. Ordinary Studio Palembang, Palembang. Diakses 04 September 2020, dari core.ac.uk.

[12] Muhammad Fajri Prakasa, Ramadhan, Desi Pibriana, Muhammad Rizky Pribadi 2018, Rancang Bangun Sistem Informasi E-Business Berbasis Website Studi Kasus Pada PT Pandawa Untuk Indonesia Palembang, Palembang. Diakses 04 September 2020, dari core.ac.uk.

[13] Ragil, Wukil 2010, Analisis Menggunakan Metode Pieces, Jakarta.

[14] Riana Lismi Aprianti, Meyti Sabrina, M. Havis Irfani 2018, Sistem Informasi E-Business Pada CV. Central Medica Berbasis Website, Palembang. Diakses 13 September 2020, dari core.ac.uk.

[15] Saputra, Agus 2018, Panduan Praktis dan Jitu Menguasai PHP dan SQL Server 2017, $C V$. Asfa Solution, Cirebon. 
[16] Sibero, Alexander F.k 2013, Web Programing Power Pack, Media Kom, Jakarta.

[17] Sidik, Bertha 2012, Pemrograman Web Dengan HTML, Informatika, Bandung.

[18] Sri Julianti 2017, Mastering Packaging For E-Commerce Strategi dan Teknik Mengemas Produk Secara Aman dan Mengesankan, Gramedia Pustaka Umum, Jakarta.

[19] Steven Alter 2002, Information System: Foundation of E-Business, Prentice Hall.

[20] Susanti 2015, E-Business Modeling Fashionable Hijab, Kudus. Diakses 04 September 2020, dari eprints.umk.ac.id. 